\title{
IMPLEMENTASI PERMENDIKBUD NO. 111 TAHUN 2014 TENTANG BIMBINGAN DAN KONSELING DI SEKOLAH DASAR DAN MENENGAH DALAM PERBAIKAN KUALITAS MATERI PERKULIAHAN
}

\author{
Muhammad Ferdiansyah ${ }^{1}$, Romadhona Noverina ${ }^{2}$ \\ Universitas PGRI Palembang ${ }^{1}$ \\ Universitas PGRI Palembang ${ }^{2}$ \\ Email: mferdiansyah34@yahoo.com
}

\begin{abstract}
ABSTRAK
Sejak munculnya regulasi tentang $B K$ pada periode ke lima gerakan $B K$ di Indonesia,hal ini semakin memperkokoh BK dalam ranah pendidikan. Penelitian bertujuan untuk mengevaluasi, memberikan sumbangan ide dan gagasan dalam upaya melakukan revisi terhadap kurikulum di program studi BK khususnya di Universitas PGRI Palembang. Penelitian ini adalah penelitian deskriptif kualitatif. Teknik pengumpulan data dengan wawancara, observasi, dokumentasi dan FGD. Penentuan informan menggunakan teknik purposive sampling. Temuan penelitian diperiksa melalui empat kreteria yaitu (1) uji Kepercayaan 2) Keteralihan, 3) Defendibilitas 4) Konformitas. Hasil penelitian ditemukan bahwa a) struktur telah dilakukan revisi b) Permendikbud No. 111 tentang BK telah dijadikan acuan dalam menyusun materi perkulihan c) Permendikbud No. 111 tentang BK di sakolah dasar dan menengah membantu dosen dalam mengembangkan materi perkuliahan yang kreatif dan inovatif.
\end{abstract}

Kata Kunci: Implementasi, Permendikbud No. 111 tentang BK, Materi Perkuliahan

\section{IMPLEMENTATION PERMENDIKBUD NO. 111 OF 2014 CONCERNING MENTORING AND CONSELING IN THE PRIVATE VOCATIONAL SCHOOL AND MEDIUM OF QUALITY IMPROVEMENT OF EDUCATION MATERIALS}

\begin{abstract}
Recently the emergence of regulations on $B K$ in the fifth period of the $B K$ movement in Indonesia, in this is cased increasingly and strengthening $B K$ in the realm of education. Research aims to evaluate, contribute ideas and ideas which is an effort to revise towards the curriculum in the BK study program, especially at Palembang PGRI University. This research is a qualitative descriptive study. Data collection techniques are collected interview, observation, documentation and FGD. Determination of informants are using techniques purposive sampling. Research findings were examined through four criteria, namely (1) test Trust 2) Pass ability, 3) Deficiency 4) Conformity. The results of the study were found that a) the structure has been
\end{abstract}


revised b) Permendikbud No. 111 about BK has used as a reference in preparing the material for recovery c) Permendikbud No. 111 about BK elementary and secondary schools assist lecturers in developing material creative and innovative lectures.

\section{Keywords: Implementation, Permendikbud No. 111 concerning BK, Lecture Materials}

\section{PENDAHULUAN}

Kurikulum 2013 (selanjunya di singkat K-13) adalah kurikulum yang berlaku dalam sistem pendidikan Indonesia saat ini. K-13 merupakan kurikulum penganti kurikulum 2006 (KTSP) yang telah berlaku selama lebih kurang 6 tahun. Pada tahun 2013/2014, K-13 telah diimpelementasikan secara terbatas pada sekolah perintis, yakni pada kelas I dan IV untuk tingkat sekolah dasar, kelas VII untuk SMP, dan kelas X untuk jenjang SMA/SMK, sedangkan pada tahun 2014, K13 sudah diterapkan di kelas I, II, IV, dan V sedangkan untuk SMP Kelas VII dan VIII dan SMA Kelas X dan XI. Jumlah sekolah yang menjadi sekolah perintis adalah sebanyak 6.326 sekolah tersebar di seluruh provinsi di Indonesia. (wikipedia.org/wiki/Kurikulum_2013).

Pada K-13, terlihat jelas bahwa guru BK mengambil peran yang penting, hal ini ditandai dengan program peminatan peserta didik. Peminatan yang dimaksud pada K-13 merupakan suatu proses pemilihan dan pengambilan keputusan oleh peserta didik yang didasarkan atas pemahaman potensi diri dan peluang yang ada pada satuan pendidikan. Muatan peminatan peserta didik meliputi peminatan kelompok mata pelajaran, lintas peminatan, pendalaman peminatan dan ekstra kurikuler. Dalam konteks tersebut, layanan BK diharapkan dapat membantu peserta didik untuk memahami, menerima, mengarahkan, mengambil keputusan, dan merealisasikan keputusan dirinya secara bertanggungjawab, sehingga mencapai kesuksesan, kesejahteraan dan kebahagiaan dalam kehidupannya. Harapan tersebut sejalan dengan tujuan dan tugas guru BK di sekolah dalam bidang karir yaitu, membantu peserta didik dalam merencanakan, memilih, dan berupaya mendorong peserta didik untuk meraih karir dan mewujudkan kehidupan yang produktif dan sejahtera.

Program studi BK Universitas PGRI Palembang, sebagai salah satu lembaga pendidikan yang menjadi wadah menyiapkan calon tenaga guru BK 
profesional, tentu saja harus ikut berperan aktif dalam meningkatkan kualitas lulusannya. Seiring dengan itu mahasiswa BK perlu dibekali seperangkat wawasan, pengetahuan, keterampilan dan sikap untuk merespon percepatan kemajuan zaman tersebut. Untuk mencapai hal tersebut, dosen sebagai salah satu komponen penting dalam sebuah lembaga pendidikan yang betugas mentransformasikan ilmu pengetahuan di program studi BK harus mampu membekali mahasiswa dengan strategi atau metode baru dalam bidang BK. Untuk itu materi yang akan diajarkan tentu saja harus memiliki standar dan tujuan pencapain yang jelas. Agar dapat menghasilkan lulusan yang berkualitas.

Merujuk pada penjelasan tersebut, disadari bahwa sebagai satu-satunya Perguruan Tingi Swasta yang menyelenggrakan program studi BK di Sumatera Selatan, program studi BK masih belum maksimal dalam dalam membantu penyelengaraan BK secara profesional di sekolah khususnya di Sumatera Selatan. Hal ini diperkuat denga penelitian yang dilakukan oleh Ferdiansyah, M \& Efrianto (2018:93) menemukan bahwa pola guru BK dalam (alumni Universitas PGRI Palembang) dalam penganan siswa bermasalah masih dominan menggunakan pendekatan disiplin. Selanjutanya penelitian lain yang dilakukan oleh Ferdiansyah, M \& Efrianto (2016:98) di program studi BK Universitas PGRI Palembang menemukan bahwa lemahnya keterampilan mahasiswa tingkat akhir dalam menyusun skripsi penelitian kualitatif dan hal ini berakibat pada lemahnya kompetensi mahasiswa BK dalam pelaksanaan konseling khusnya pada teknik mengeksplorasi masalah pribadi klien atau konseli.

Berdasarkan temuan penelitian tersebut tentu saja berbagai upaya perbaikan sedang diupayakan oleh program studi BK dalam memaksimalkan kualitas mahasiswa dan lulusan agar mampu berkontribusi besar dalam perbaikan kualitas pembelajaran di sekolah. Sebagai upaya untuk mencapai tujuan tersebut, pemerintah juga berupaya memfasilitasi dengan mengeluarkan berbagai peraturan untuk pencapaian tujuan tersebut, salah satunya adalah mengeluarkan Permendikbud Normor 111 tentang BK di Sekolah Dasar dan Menengah. Keberadaan peraturan ini tentu berimbas pada berbagai aspek, salah satunya adalah setiap tingkat pendidikan dasar dan menengah perlu melaksanakan layanan BK secara professional, dengan demikian Permendikbud Nomor 111 tahun 2014 
dan kurikulum menghendaki dilaksanakan kegiatan layanan BK di sekolah, termasuk di sekolah dasar. Oleh karena itu Permendikbud Nomor 111 menjadi rujukan penting, khususnya bagi guru BK dalam menyelenggarakan dan mengadministrasikan layanan BK di sekolah.

Mencermati lebih jauh peraturan ini, peneliti melihat ada perubahan dari kehadiran peraturan menteri ini yaitu secara resmi mulai diterapkannya pola "BK Komprehensif", sebagai pengganti dari pola BK 17 sebagaimana diisyaratkan dalam Pasal 6 ayat 1 yang menyebutkan bahwa: "Komponen layanan BK memiliki 4 (empat) program yang mencakup: (a) layanan dasar; (b) layanan peminatan dan perencanaan individual; (c) layanan responsif; dan (d) layanan dukungan sistem”. Merujuk pada hal itu tentu saja akan berdampak pada segenap administrasi dan materi pelayanan BK. Lebih jauh melihat penjelasan pada pasal 1, Permendikbud Nomor 111 tahun 2014 tentang BK di Sekolah dasar dan menengah dijelaskan bahwa, BK merupakan suatu upaya yang dirancang secara sistematis, logis, dan berkelanjutan serta terprogram yang dilakukan oleh konselor atau guru BK untuk memfasilitasi perkembangan peserta didik/konseli untuk mencapai kemandirian dalam kehidupannya.

Sejalan dengan apa yang dijelaskan pada penjelasan pasal 1 tersebut Prayitno (2012: 8) menjelaskan bahwa BK adalah proses pemberian bantuan yang dilakukan oleh orang yang ahli kepada seseorang atau beberapa orang individu, baik anak-anak, remaja, maupun dewasa agar orang-orang yang dibimbing dapat mengembangkan kemampuan dirinya sendiri dan mandiri, dengan memanfaatkan kekuatan individu dan sarana yang ada dan dapat dikembangkan berdasarkan norma-norma yang berlaku. Menimak kedua penjelasan tersebut dapat dipahami bahwa pelaksanaan konseling bertumpu pada kualitas individu dalam memfasilitasi perkembanga siswa. Hal ini jelas bahwa hubungan konseling bukanlah sebuah hubungan yang menekankan hukuman atau pendekatan disiplin.

Penyelenggaraan BK tidak bisa terlepas dari komponen pendidikan di sekolah yang bisa dilihat pada gambar berikut 


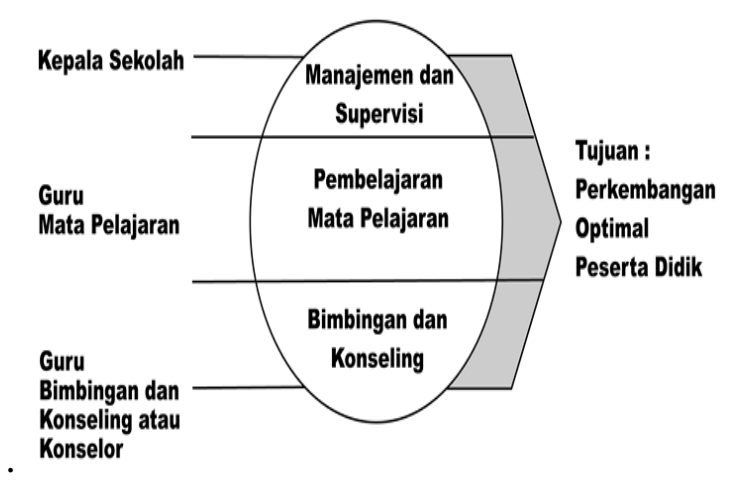

\section{Gambar 1. kompenen pendidikan di sekolah}

Melihat gambar 1 dapat dimakanai bahwa terdapat tiga komponen penting dalam pelakasanaan pendidikan di sekolah dimana bidang manajemen dan supervisi merupakan tugas pokok dan fungsi dari kepala sekolah, selanjutnya guru mata pelajaran bertugas dalam memberikan penguasaan materi pelajaran di sekolah dan guru BK berperan dalam pelaksanan konseling di sekolah. Oleh karena itu materi pembelajaran menempati posisi yang sangat penting dari keseluruhan kegiatan belajar mengajar, sehingga harus dipersiapkan agar pelaksanaan pembelajaran dapat mencapai sasaran yang sesuai dengan Standar Kompetensi dan Kompetensi Dasar.

Berkenaan dengan itu Farozin (2017) menjelaskan bahwa dalam penyusunan materi pembelajaran, pendidik perlu memperhatikan relevansi dengan tujuan pencapaian standar kompetensi dan kompetensi dasar, selanjutnya materi pembelajaran harus memiliki konsistensi dengan tujuan pencapaian standar kompetensi dan kompetensi dasar, dan adquency materi pembelajaran yang diajarkan hendaknya cukup memadai dalam membantu peserta didik menguasai konpetensi dasar yang diajarkan. Materi tidak boleh terlalu sedikit dan tidak boleh terlalu banyak. Jika terlalu sedikit maka kurang membantu tercapainya standar kompetensi dan kompetensi dasar. Sebaliknya jika terlalu banyak maka akan mengakibatkan keterlambatan dalam pencapaian target kurikulum.

Mencermati ketiga hal tersebut maka pertanyaan penelitian ini adalah bagaimana Implementasi permendikbud nomor 111 tentang BK di sekolah dasar dan menengah dalam perbaikan kualitas materi pembelajaran? 


\section{METODE PENELITIAN}

Penelitian ini adalah penelitian kualitatif dengan tipe eksplanasi deskriptif (Ferdiansyah, M: 2015). Penelitian kualitatif ini dipilih dengan alasan untuk melihat proses yang telah dilakukan oleh program studi BK Universitas PGRI Palembang beberapa tahun kebelakang, dalam melakukan upaya perbaikan kualitas materi perkulihan.

Oleh karena untuk mendapatkan data yang tepat peneliti mengunakan teknik purposive sampel dalam menentukan informan. Informan penelitian merupakan orang yang dimanfaatkan untuk memberikan informasi tentang situasi dan kondisi latar penelitian (Moleong, 1998:90). Temuan penelitian selanjutnya diuji keabsahan melalui empat kreteria yaitu (1) uji Kepercayaan (2) uji Keteralihan, (3) uji Defendibilitas (4) uji Konformitas (Yusuf 2013:396). Selanjutnya data dianalisis dengan mengacu pada model alir yang dikemukakan oleh Miles dan Huberman (dalam Sugiyono, 2015) yang mencangkup tiga kegiatan yang bersamaan reduksi data, penyajian data dan penarikan kesimpulan, reduksi data, penyajian data, penarikan kesimpulan.

\section{PEMBAHASAN}

Berdasarkan temuan penelitian selama di lapangan ditemui berbagai fenomena yang diharapkan dapat menjadi bahan evaluasi bagi program studi BK Fakultas Keguruan dan Ilmu Pendidikan Universitas PGRI Palembang dalam upaya memperbaiki kualitas materi perkuliahan, agar hasil penelitian ini mudah dipahami berikut peneliti jelaskan berasarkan fokus dan tujuan penelitian. Setelah peneliti melakukan kegiatan pengumpulan data melalui wawancara, pengamatan, studi dokumentasi dan FGD dari bulan April 2018 sampai dengan September 2018.

Berdasarkan hasil wawancara dengan dosen dan mahasiswa yang menjadi informan penelitian. Diperoleh data bahwa pada tahun 2015 program studi dengan segenap dosen yang ada telah berupaya untuk menjadikan Permendikbud no. 111 tahun 2014 tentang BK di sekolah dasar dan menengah sebagai rujukan dalam mengembangkan kurikulum beserta perangkat pembelajarannya. Keseriusan program studi BK ini ditunjukkan dengan mendatangkan beberapa pakar BK di 
Indonesia untuk mensosialisasikan dan memberikan workshop dalam penyusunan kurikulum dan perangkat pembelajaran. Berdasarkan temuan penelitian, maka peneliti melihat bahwa ada beberapa hal yang telah berhasil dilakukan oleh program studi BK dalam memperbaiki kulitas materi perkuliahan.

Menurut data yang diperoleh peneliti, sejak diterbitkannya Permendikbud no.111 tahun 2014 tentang BK di sekolah dasar dan menengah pihak program studi BK mulai melakukan diskusi rutin terkait dengan perbaikan kualitas materi pembelajaran. Sebagaimana diisyaratkan dalam Pasal 6 ayat 1 yang menyebutkan bahwa: "Komponen layanan BK memiliki 4 (empat) program yang mencakup: (a) layanan dasar; (b) layanan peminatan dan perencanaan individual; (c) layanan responsif; dan (d) layanan dukungan sistem" dari penjelasan pasal 6 ayat 1 tersebut dipahami bahwa pola BK yang selama ini dijalankan di program studi BK Universitas PGRI Palembang yang mulanya menggunakan Pola BK 17+ kini menjadi Pola BK Komprehensif. Oleh karena itu materi yang ada mulai disesuaikan dengan materi BK Komprensif. Selain itu peneliti mendapatkan keterangan dari salah seorang dosen "ED" yang menyatakan bahwa selama ini dalam penyusunan materi perkuliahan dosen memiliki materi perkulihan yang berbeda walaupun mata kuliahnya sama (wawancara 17 Mei 2018) dari keterangan tersebut diperoleh informasi bahwa tidak ada keseragaman dosen dalam menyusun materi perkuliahan walaupun mata kuliahnya sama, dalam artian mata kuliah sama namun kelas berbeda maka mahasiswa akan mendapatkan materi yang berbeda. Sehingga ketika diselengarakan Ujian Akhir Semester mahasiswa kadang mengalami kebingungan karena materi yang dipelajari berbeda dengan soal yang muncul pada saat Ujian Akhir Semester. Dikarenakan pada saat itu dosen yang menyusun soal Ujian Akhir semester adalah dosen yang memiliki jenjang akademik yang lebih tinggi. Lebih jauh lagi peneliti menemukan juga bahwa masih ada beberapa dosen yang belum mengumpulkan silabus, belum sama format penyusunan silabus. Berbagai permasalah tersebut akhirnya mulai diatasi pada tahun 2016, seluruh tim dosen diajak untuk memulai komitmen untuk membangun sistem perkuliahan berdasarkan perencanaan yang relevan dengan tujuan, ranah belajar dan hirarkinya. Penyusunan materi kuliah harus didasarkan dengan kurikulum yang berlaku meliputi penyusunan silabus, satuan acara 
perkuliahan dan bahan ajar. Mekanisme peyusunan materi perkuliahan pun dibangun dengan mengacu pada permendikbud no 111 tahun 2014 tentang BK di sekolah dasar dan menengah. Selain itu pihak program studi mendorong semua dosen untuk menghadari rapat keordinasi dosen pada setiap kelompok dosen bidang keahlian. Hasilnya saat ini setiap dosen hampir semuanya memiliki bahan ajar dan modul dalam pelaksanaan perkuliahan yang disusun sesuai dengan kurikulum yang berlaku.

\section{Perbaikan Kurikulum}

Struktur dan isi kurikulum yang ditawarkan di program studi BK FKIP Universitas PGRI Palembang pada dasarnya mengacu pada kebijakan operasional tentang kurikulum sebagaimana diatur dalam SK Mendiknas RI Nomor: 232/U/2000 tanggal 20 Desember 2000, tentang Pedoman Penyusunan Kurikulum Pendidikan Tinggi dan Penilaian Hasil Belajar Mahasiswa dan Keputusan Mendiknas nomor: 045/U/2002 tentang Kurikulum Inti Pendidikan Tinggi dan Buku Pedoman Akademik Universitas PGRI Palembang. Kegiatan pengembangan dan peningkatan kurikulum di bawah tanggungjawab Wakil Dekan I FKIP UPGRI Palembang (bidang akademik) yang dilakukan bersama Ketua Jurusan Ilmu Pendidikan, Ketua program studi BK, Sekretaris PSBK, serta melibatkan dosen, tenaga ahli/pakar, stakeholder, dan alumni. Kegiatan meliputi perencanaan (analisis kebutuhan pasar, pemangku kepentingan dan analisis keilmuan dan keahlian serta selaras dengan visi dan misi universitas dan fakultas), pelaksanaan dan pengembangan kurikulum (mengacu kepada Keputusan Mendiknas nomor: 045/U/2002 tentang Kurikulum Inti Pendidikan Tinggi dan Buku Pedoman Akademik UPGRI Palembang), dan mengkoordinasikan kegiatan penyusunan kurikulum dalam kurun waktu tahun akademik 2006/2007 dan 2011/2012. PSBK sekurang-kurangnya telah melakukan 2 (dua) kali perbaikan dan penyempurnaan kurikulum.

Berdasarkan temuan penelitian saat ini PSBK telah menyusun kurikulum baru mengacu mengacu pada Kerangka Kualifikasi Nasional Indonesia (KKNI) yang telah diterapkan pada tahun akademik 2016/2017 sesuai Permenristek Dikti No. 44 tahun 2015. Selain itu dalam penyusunan kompetensi utama lulusan 
program studi banyak mengacu pada permendikbud no. 111 tahun 2014 tentang BK di sekolah dasar dan menengah dimana kurikulum 2011 dilakukan peninajauan kurikulum dan hasilnya sebagai berikut:

\begin{tabular}{|c|c|c|c|c|c|c|c|c|}
\hline \multirow[b]{2}{*}{ No } & \multirow[b]{2}{*}{ No. MK } & \multirow[b]{2}{*}{ Nama MK } & \multirow{2}{*}{$\begin{array}{c}\text { MK } \\
\text { Baru/ } \\
\text { Lama/Hapus }\end{array}$} & \multicolumn{2}{|c|}{ Perubahan pada } & \multirow[b]{2}{*}{$\begin{array}{c}\text { Alasan } \\
\text { Peninjauan }\end{array}$} & \multirow{2}{*}{$\begin{array}{c}\text { Atas } \\
\text { usulan/ } \\
\text { masukan } \\
\text { dari }\end{array}$} & \multirow{2}{*}{$\begin{array}{c}\text { Berlaku } \\
\text { mulai } \\
\text { Sem./ } \\
\text { Th. }\end{array}$} \\
\hline & & & & $\begin{array}{l}\text { Silabu } \\
\text { s/RPS }\end{array}$ & $\begin{array}{l}\text { Buku } \\
\text { Ajar }\end{array}$ & & & \\
\hline (1) & (2) & (3) & (4) & (5) & (6) & (7) & (8) & (9) \\
\hline 1 & MKPK 231 & $\begin{array}{l}\text { BK Pribadi } \\
\text { Sosial }\end{array}$ & Hapus & - & 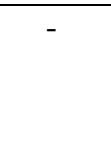 & $\begin{array}{l}\text { Tumpang tindih } \\
\text { dengan MK } \\
\text { Psikologi sosial }\end{array}$ & $\begin{array}{l}\text { Rapat } \\
\text { prodi dan } \\
\text { Stake } \\
\text { Holder }\end{array}$ & 2013 \\
\hline 2 & MKPB 232 & $\begin{array}{l}\text { Praktikum } \\
\text { Teknik Tes } \\
\text { /Nontes }\end{array}$ & Hapus & - & - & $\begin{array}{l}\text { Tumpang tindih } \\
\text { dengan MK } \\
\text { Pemahaman } \\
\text { Individu I } \\
\end{array}$ & $\begin{array}{c}\text { Rapat } \\
\text { prodi dan } \\
\text { Stake } \\
\text { Holder } \\
\end{array}$ & 2013 \\
\hline 3 & MKBB351 & $\begin{array}{l}\text { Metodelogi } \\
\text { Penel.\&Pendi } \\
\text { dikan BK }\end{array}$ & Lama & $\sqrt{ }$ & $\sqrt{ }$ & $\begin{array}{l}\text { Penyesuaian } \\
\text { perkembangan } \\
\text { sekolah dan } \\
\text { DUDI }\end{array}$ & $\begin{array}{l}\text { Dosen, } \\
\text { Sekolah }\end{array}$ & 2014 \\
\hline 4 & MKKB358 & $\begin{array}{l}\text { BK Lintas } \\
\text { Budaya }\end{array}$ & Lama & $\sqrt{ }$ & $\sqrt{ }$ & $\begin{array}{l}\text { Penyesuaian } \\
\text { perkembangan } \\
\text { sekolah dan } \\
\text { DUDI }\end{array}$ & $\begin{array}{c}\text { Rapat } \\
\text { prodi } \\
\text { Stake } \\
\text { Holder } \\
\end{array}$ & 2014 \\
\hline 5 & MKBB121 & $\begin{array}{l}\text { Pengantar } \\
\text { Komunikasi } \\
\text { Jurnalistik }\end{array}$ & Hapus & $\sqrt{ }$ & $\sqrt{ }$ & $\begin{array}{l}\text { Kurang relevan } \\
\text { dengan BK }\end{array}$ & $\begin{array}{l}\text { Saran } \\
\text { pakar }\end{array}$ & 2015 \\
\hline 6 & MKB 123 & $\begin{array}{l}\text { Landasan } \\
\text { Sosial } \\
\text { Budaya BK }\end{array}$ & Baru & $\sqrt{ }$ & $\sqrt{ }$ & $\begin{array}{l}\text { Saran dari } \\
\text { stakeholder }\end{array}$ & $\begin{array}{l}\text { Saran } \\
\text { pakar }\end{array}$ & 2016 \\
\hline 7 & MKB 234 & BK di PAUD & Baru & $\sqrt{ }$ & $\sqrt{ }$ & $\begin{array}{l}\text { Hasil temu } \\
\text { kolegeal dengan } \\
\text { forum prodi BK }\end{array}$ & $\begin{array}{l}\text { Stake } \\
\text { Holder }\end{array}$ & 2016 \\
\hline 8 & MKB 237 & BK di PLK & Baru & $\sqrt{ }$ & $\sqrt{ }$ & $\begin{array}{l}\text { Hasil temu } \\
\text { kolegeal dengan } \\
\text { forum prodi BK }\end{array}$ & $\begin{array}{l}\text { Stake } \\
\text { Holder }\end{array}$ & 2016 \\
\hline 9 & MKP 241 & $\begin{array}{l}\text { Teori dan } \\
\text { Pengembanga } \\
n \text { media BK }\end{array}$ & Baru & $\sqrt{ }$ & $\sqrt{ }$ & $\begin{array}{l}\text { Hasil temu } \\
\text { kologeal dengan } \\
\text { forum prodi BK }\end{array}$ & $\begin{array}{c}\text { Rapat } \\
\text { prodi } \\
\text { Stake } \\
\text { Holder }\end{array}$ & 2016 \\
\hline 10 & MKB 244 & $\begin{array}{l}\text { BK di } \\
\text { SD\&SM }\end{array}$ & Baru & $\sqrt{ }$ & $\sqrt{ }$ & $\begin{array}{l}\text { Hasil temu } \\
\text { kologeal dengan } \\
\text { forum prodi BK }\end{array}$ & $\begin{array}{c}\text { Rapat } \\
\text { prodi dan } \\
\text { StakeHold } \\
\text { er } \\
\end{array}$ & 2016 \\
\hline
\end{tabular}

Sumber: Dokumen Kurikulum Program Studi BK Universitas PGRI Palembang

Berdasarkan dokumen kurikulum tersebut dapat dipahami bahwa mekanisme perubahan kurikulum telah dilakukan berdasarkan pertimbangan dan alasan yang jelas, diantaranya dari hasil pertemuan dengan alumni, pengguna dan 
yang terbaru adalah dari temu kologeal/forum prodi BK Indonesia yang telah dilakukan beberapa kali yaitu di Gorontalo, Surabaya dan Yogyakarta.

\section{Indikator Keberhasilan Perbaikan Kualitas Materi Perkuliahan}

Berdasarkan data temuan penelitian diperoleh informasi bahwa sejak dikeluarkannya Permendikbud no. 111 tentang BK di sekolah dasar dan menengah dan diiringi dengan diterbitkannya Pedoman Operasional Penyelengaraan BK dari GTK semakin memperjelas pelaksanaan perkuliahan di program studi BK FKIP Universitas PGRI Palembang. Hal ini ditandai dengan lengkapnya data perangkat perkuliahan yang ada di program studi. Untuk lebih jelas dapat peneliti sajikan data perbaikan kualitas materi perkuliahan di program studi BK FKIP Universitas PGRI Palembang;

\begin{tabular}{|l|l|l|}
\hline Komponen Pendidikan & $\begin{array}{c}\text { Sebelum Mengimplementasikan } \\
\text { Permendikbud no. 111 tahun } \\
\text { 2014 tentang BK di Sekolah } \\
\text { Dasar dan Menengah }\end{array}$ & $\begin{array}{c}\text { Setelah Mengimplementasikan } \\
\text { Permendikbud no. 111 tahun } \\
\text { 2014 tentang BK di Sekolah } \\
\text { Dasar dan Menengah }\end{array}$ \\
\hline Silabus & Ada namun belum seragam & Seragam \\
\hline Materi kuliah & Tidak seragam & Seragam \\
\hline Modul Matakuliah Praktek & Tidak ada & Ada \\
\hline Bahan Ajar & Ada 60\% & $80 \%$ \\
\hline Soal Ujian Akhir Semester & Tidak Seragam & Seragam \\
\hline Buku Ajar Ber ISBN & Belum ada & Ada (3 Judul buku) \\
\hline Kurikulum & Kurikulum 2011 & Kurikulum 2016 (KKNI) \\
\hline Akreditasi Prodi & Nilai 300 (B Kurus) & Nilai 348 ( B gemuk) \\
\hline
\end{tabular}

Berdasarkan penyajian data tersebut maka dapat disimpulkan bahwa pengimplemtasian permendikbud no. 111 tahun 2014 tentang BK di sekolah dasar dan menengah memberikan dampak yang baik dalam perbaikan dalam berbagai aspek penyelengaraan pendidikan di program studi BK FKIP Universitas PGRI Palembang.

\section{PENUTUP}

\section{KESIMPULAN}

Dengan di implementasikannya Permendikbud Nomor 111 Tahun 2014 Tentang BK Pada Pendidikan Dasar dan Menengah patut disyukuri oleh guru BK / konselor di Indonesia. Karena telah membawa dampak positif bagi perbaikan kalitas materi perkuliahan dan bagi keseragaman penyelengaraan pendidikan 
khususnya di program studi BK FKP Universitas PGRI Palembang. Namun dengan diimplementasikannya peraturan menteri tersebut bukan tidak ada koreksi, atau hambatan. seperti kita ketahui bahwa setiap terbitnya suatu peraturan mesti ada kelebihan dan kekurangannya hal ini terlihat pada saat peneliti mengumpulkan data di lapangan. Demikian juga dengan Peraturan Menteri tersebut.

\section{SARAN}

Berdasarkan temuan penelitian tersebut maka peneliti menyarankan kepada perangkat/personil penyelengara program studi untuk memiliki komitmen yang kuat dalam menyelengarakan pendidikan yang profesional, sehingga penyelengaraan pendidikan sekarang yang telah baik dapat dipertahankan dan ditingkatkan kembali dalam rangka menghasilkan mahasiswa dan lulusan yang berkualitas dan berkontribusi besar bagi penyelengaraan pelayanan konseling di dunia pendidikan.

\section{DAFTAR RUJUKAN}

Farozin. 2017. Pedoman dan Panduan Bimbingan dan Konseling. Palembang : Makalah Sosialisasi POP.

Ferdiansyah, M \& Efrianto. 2018. Pola Guru Bimbingan dan Konseling dalam Penanganan Siswa Bermasalah di SMA PGRI 4 Palembang.. Journal of Innovative Counseling : Theory, Practice \& Research, 1 (1): pp. 91-94.

Ferdiansyah, M. 2016. Asesmen terhadap Keterampilan Mahasiswa Bimbingan dan Konseling dalam Menyusun Skripsi Penelitian Kualitatif. Jurnal Fokus Konseling : Volume. 2 No. 2. Hlm. 126-135.

Ferdiansyah, M. 2015. Dasar Penelitian Kualitatif. Bogor: Herya Media.

Moleong. 1998. Metodelogi Penelitian Kualitatif. Bandung: Remaja Rosdakarya.

Permendikbud Nomor 111 tahun 2014 tentang bimbingan dan konseling pada pendidikan dasar dan pendidikan menengah. Jakarta pemerintah Republik Indonesia.

Prayitno. 2012. Wawasan Profesional Bimbimbingan dan Konseling. Padang: UNP Press.

Sugiyono. 2015. Metodologi Penelitian Kuantitatif, Kualitatif dan $R$ dan $D$. Bandung: Alfabeta.

Yusuf. A. Muri 2013. Metode Penelitian; Kuantitatif, Kualitatif dan Penelitian Gabungan. Padang: UNP Press. 